\title{
Tras las huellas de una ilusión: el Partido Comunista argentino y sus planteos del Frente Democrático Nacional (1955-1963)
}

\section{Hernán Camarero}

Conicet / UBA

hercamarero@gmail.com

Desde fines de la década de 1920 (más exactamente a partir del VIII Congreso, de 1928), el Partido Comunista de la Argentina radiografió la estructura socioeconómica del país en términos de un capitalismo deformado por la dependencia con el imperialismo, el peso del latifundio y los resabios semifeudales. De alli derivó su caracterización central: el país requería una revolución por etapas, "democrático-burguesa, agraria y antiimperialista". Estos planteos, surgidos cuando la Comintern aplicaba la estrategia de clase contra clase, se afianzaron y a la vez adquirieron nuevos perfiles con la adopción del frente popular (1935), balanceado y profundizado en el IX Congreso de 1938 y en el X Congreso de 1941. Tras ello, el horizonte socialista se hizo aún más indeterminado. A partir de estas definiciones se postulaba que la clase obrera poseía aliados naturales en el campo de la burguesía nacional desvinculada del capital extranjero y la oligarquía terrateniente. Lo que siguió de allí en más y durante medio siglo fueron meras adecuaciones a esos lineamientos.

El objetivo de este artículo es examinar la aplicación de esta línea durante un periodo casi inexplorado por la historiografia sobre el PC. ${ }^{1}$ Nos referimos al lapso que se abrió con el derrocamiento del gobierno de Juan D. Perón en 1955, continuó con la dictadura cívico-militar autodenominada Revolución Libertadora y culminó con la presidencia de Arturo Frondizi, la cual fue depuesta por un nuevo golpe militar en 1962. Esa etapa estuvo signada por varios procesos simultáneos, que impactaron en los análisis del PC de un modo u otro: el intento de la burguesía por imponer un nuevo régimen de acumulación del capital (en buena medida, basado en proyectos de racionalización productiva y de retroceso en el nivel de ingreso de los asalariados); la resistencia que la clase obrera ofreció a esta ofensiva; las medidas de exclusión y

1. Para una reflexión acerca de la historiografia sobre el PC argentino: Cernadas, Pittaluga y Tarcus, 1998; Campione, 2007; Camarero, 2013. 
proscripción del peronismo como fuerza e identidad política; la profunda inestabilidad socio-política, toda vez que no sólo operó una confrontación del Estado y el capital contra los trabajadores, sino que también afloraron las contradicciones en el seno de la clase dominante, arrastrada a enfrentamientos internos y un "empate hegemónico", que tiñó el ciclo bajo el signo de una ingobernabilidad crónica; y, en contexto continental, las tendencias a la radicalización ideológico-política que comenzó a habilitar el triunfo de la revolución cubana.

En función de reconstruir las caracterizaciones y planteamientos estratégicos del PC durante estos años, apelamos al estudio de algunas de sus fuentes más relevantes (libros, folletos, informes y documentos) y de sus dirigentes más encumbrados, aquellas que sirven, precisamente, para observar los posicionamientos centrales del partido. ${ }^{2}$ Seleccionamos los escritos que consideramos imprescindibles, para poder examinar los discursos y los contextos de la enunciación comunista de su principal apuesta política, la que estaba referida al tipo de revolución a realizarse en la Argentina y cómo tenía que ser el instrumento político capaz de vehiculizarla. Como explicamos en detalle, si se promovía una "revolución democrático-burguesa, agraria y antiimperialista", el sujeto socio-político en condiciones de propiciar esa transformación era el denominado Frente Democrático Nacional. ¿Contra qué y quiénes se enfrentaría esta revolución y cuáles serian sus objetivos y beneficiarios principales? ¿Qué papel desempeñarian las distintas clases y fracciones de clase? ¿De qué manera entendian los comunistas la dinámica interna, las fases y las tareas planteadas en dicha revolución y qué concepciones ofrecian sobre las formas de acceso al poder? ¿Cómo se balanceaba el comportamiento de los actores o factores políticos, como el peronismo, el régimen de la Revolución Libertadora, el frondicismo y las izquierdas? ¿Cuál era el lugar asignado al propio PC en todo este proceso? He aquí algunas de las preguntas fundamentales que intentaremos responder en las páginas que siguen.

\section{La propuesta inalterable del Frente Democrático Nacional: de la década peronista a la Revolución Libertadora}

La aparición del peronismo, en la coyuntura existente entre 19431945, significó un duro revés para el PC. Tras casi dos décadas de crecimiento en la clase obrera, sobre todo en el sector industrial, el

2. Casi no existe bibliografia referida a este período del PC. Lo escrito desde el propio partido carece de sustancia y confirma los niveles de elaboración teórico-política del estalinismo: Fava, 1983; Arévalo, 1983. 
partido vio esfumarse una buena parte de la influencia sindical y política alcanzada (Camarero, 2012). Tal como hemos señalado en ése y otros trabajos, confluyeron factores internos y externos: el impacto de la propia estrategia partidaria de frentepopulismo antifascista, que disolvió las prácticas combativas y clasistas del plano sindical en un colaboracionismo de clases en el aspecto político-programático; el avasallante triunfo de proyecto nacional-populista burgués encarnado por Perón, que desplazó a las izquierdas del movimiento obrero, conduciendo a éste a otro tipo de integración social y política heterónoma, de escala e intensidad increíblemente vasta.

El procesamiento de la derrota electoral de 1945-1946 no fue fácil. En términos de sufragios, no sólo perdió la Unión Democrática que el PC conformó junto a diversas fuerzas, sino que las propias listas legislativas del partido sólo recibieron unos 150.000 votos (diez veces menos que la triunfante coalición peronista), lo cual también demostró la falta de una maquinaria y tradición electoral en una organización condenada en los 15 años anteriores a la casi ilegalidad/clandestinidad. El partido metabolizó con cierta rapidez los cambios de la nueva situación, realizando, en agosto de 1946, su XI Congreso Nacional, en donde caracterizó las perspectivas abiertas con el flamante gobierno justicialista. La línea pasó a ser la de unir a todas las fuerzas democráticas y antiimperialistas en un Frente de Liberación Nacional y Social, al tiempo que postulaba la unidad combativa entre los sectores obreros y populares peronistas y no peronistas para superar la "demagogia social" del régimen y los límites del Plan Quinquenal. El PC decidió disolver los gremios que controlaba e ingresar a los sindicatos de la CGT peronista. Electoralmente, el partido retuvo cierto espacio: en los comicios legislativos de 1948 se acercó al $3 \%$ de los votos; pero en los presidenciales de 1951 sufrió una baja a casi el $1 \% .^{3}$

La forma organizativa del partido ya estaba definitivamente implantada: el sector dirigente aparecía consolidado en torno a las figuras centrales de Victorio Codovilla y, en segundo orden, Rodolfo Ghioldi, con Gerónimo Arnedo Álvarez ocupando formalmente el cargo de secretario general. A pesar de la relativamente fuerte homogeneidad interna de la conducción, parecen haber existido algunos matices entre sus dirigentes: un antiperonismo más acendrado en Ghioldi y más cauteloso en Codovilla, y un dirigente de creciente desarrollo, Juan José Real, que llevó esa afinidad hasta el extremo y acabó expulsado en 1953. Por otra parte, es evidente que ocurrió un cambio en el contenido social y en las

3. Sobre el PC en la década peronista: Altamirano, 2011; Penella y Fonticelli, 2007; Amaral, 2008; Gurbanov y Rodríguez, 2008; Jáuregui, 2012; Staltari, 2014 (y su artículo en este número de Archivos). 
prácticas del PC durante estos años: un partido que perdió parte de su composición obrera (aunque manteniendo muchos nichos de inserción laboral) y en donde comenzaron a tener preeminencia los sectores medios. Creció la militancia en el movimiento estudiantil y juvenil, en los barrios, sociedades de fomento y comisiones populares contra la carestía, en el ámbito intelectual, artístico y cultural o en las asociaciones de mujeres (UMA) y de derechos humanos (LADH). El aparato partidario se expandió de manera notable, convirtiéndose en una compleja maquinaria que incluía una gran cantidad de locales, propiedades, empresas de servicios sociales, bancos y cooperativas, editoriales y órganos de prensa, todo sostenido por varios miles de afiliados, militantes, simpatizantes y cuadros rentados (Gilbert, 1994 y 2009). Una estructura que, incluso, lograba sortear la recurrente represión, ya que en varios momentos durante el régimen peronista se desplegaron medidas de persecución $\mathrm{u}$ hostigamiento hacia el partido, en el contexto de profundización de la guerra fría a nivel mundial. Fenómeno que se evocaba con fuerza en el país, debido, entre otras cosas, a las campañas realizadas por los comunistas en apoyo a la URSS, las nacientes "democracias populares", la triunfante revolución china de 1949 y Corea del Norte.

El PC no definió una política de oposición clara frente a los complots, las asonadas y, finalmente, el golpe cívico-militar de septiembre de 1955. Pocos meses antes de este último, denunciaba "las medidas reaccionarias del Estado corporativo-fascista" y convocaba a "los partidos democráticos para establecer la unidad de acción". ${ }^{4}$ Cedió en varios puntos a los reclamos e iniciativas del bando "contrera" y se diferenció muy progresiva y tibiamente del hecho golpista, transcurridas varias semanas o meses de que éste se produjera. Ajustó su posición y sus formas de intervención frente a la Revolución Libertadora, el proceso de la resistencia de los trabajadores y la continuidad del peronismo como identidad política. Los comunistas vivieron un clima de expectativas en el sentido de recuperar parte del espacio perdido anteriormente, sobre todo en el movimiento obrero, y se esperanzaron con un posible fenómeno de "desperonización" de los trabajadores. Por ejemplo, Codovilla, expresando una decisión del Comité Central (CC), proclamó el 6 de enero de 1956, en un gran pic-nic en donde se festejaba el 39 aniversario de la fundación del PC, la consigna de alcanzar, mediante una intensa labor de agitación, propaganda y reclutamiento, un partido de 100.000 afiliados. Este objetivo se intentó cumplimentar a lo largo de muchos años, con resultado incierto; en todo caso, revelaba muy bien las grandes aspiraciones de expansión de la organización.

4. V. Codovilla, El leninismo y la lucha del pueblo argentino por la paz, la democracia y la independencia nacional, Buenos Aires, Anteo, 1955, pp. 45-46. 
En octubre de 1956, el CC del PC declaró abierto el período de preparación de su XII Congreso Nacional (que recién se realizó en 1963). Para comenzar con esa tarea, la dirección hizo público un Proyecto de Programa, titulado El Camino Argentino para asegurar el triunfo del pueblo en su lucha por la paz, el pan, la tierra, el bienestar social, la cultura, la democracia, la independencia nacional y el socialismo. Ese material había sido anticipado y contextualizado por el informe que Codovilla había presentado en la reunión de CC partidario de junio de ese mismo año, el cual fue editado casi al mismo tiempo en forma de libro: La nueva relación de fuerzas en lo internacional y nacional y el camino argentino hacia la democracia, la independencia nacional y el socialismo. En esa intervención-obra, Codovilla hacía un intento por enmarcar la situación argentina en el nuevo escenario mundial abierto con la propugnación de la "coexistencia pacífica" por parte del líder soviético Nikita S. Jrushchov y señalaba algunas de las derivaciones planteadas para el movimiento comunista con el XX Congreso del PC de la URSS realizado pocos meses antes, en el que la burocracia gobernante sancionó el proceso de "desestalinización", que sorprendió a casi todos en el movimiento comunista, incluyendo al propio Codovilla. El dirigente del PC local indicaba una realidad internacional signada por lo que entendía como un posible alejamiento del peligro de la guerra, debido a la creciente expansión del mundo socialista y a la progresiva articulación de éste con los pueblos coloniales en lucha y a los movimientos por la paz de diversas regiones del planeta.

Los comunistas leian el derrocamiento del régimen peronista como un momento dentro de una continuidad básica, de conservación de los mismos intereses sociales, en un devenir que anulaba cualquier rasgo radicalmente transformador a la experiencia justicialista: "El gobierno peronista mantuvo, en lo esencial, la estructura económica atrasada del país que heredó de los gobiernos oligárquicos y trató de conservarla ligando la suerte de la economía nacional a la suerte de la economía de guerra del imperialismo yanqui. Con ello no hizo más que agravar las contradicciones de toda indole existentes en nuestro país y lo llevó al borde de la catástrofe".

A un año de haber triunfado la Revolución Libertadora, en ese mismo Proyecto de Programa, el PC advertía que no podía albergarse ninguna esperanza en el nuevo régimen, pues "conserva la misma estructura económica heredada del gobierno anterior y, como aquél, aplica medidas tendientes a descargar las consecuencias de la crisis económica en desarrollo sobre las espaldas de la clase obrera, de las masas campesinas y de toda la población laboriosa en general y realiza una politica tendiente a 'resolver' la crisis mediante concesiones a los grandes latifundistas 
y a los monopolios extranjeros, los yanquis en particular". ${ }^{5}$ Había que prepararse, pues, para la continuidad de los enfrentamientos sociales, pues la población laboriosa "resiste cada día con más fuerza la ofensiva interna y la presión exterior, y aumenta su combatividad y decisión de luchar por sus reivindicaciones económicas y sociales, por las libertades sindicales, por la democracia politica y por la independencia nacional". ${ }^{6}$ El PC, a diferencia de otras corrientes mucho más pequeñas de la izquierda (los trotskistas, sobre todo), no pudo anticipar el proceso de resistencia obrera después de 1955 y lo sorprendió una vez que éste comenzó a desplegarse. Pero, en oposición al Partido Socialista y otras expresiones de la vieja izquierda, luego sí supo reacomodarse y participar de algún modo en aquel proceso de movilización y reorganización del movimiento obrero. Por supuesto, esto no lo condujo a propiciar una lucha activa contra la dictadura cívico-militar ni a postular su derrocamiento. En lo inmediato, el PC, además del reclamo de las medidas a favor de los trabajadores y sectores populares, pugnaba por formar un "gobierno de amplia coalición democrática" para que convoque a elecciones constituyentes sobre la base de la representación proporcional.

Más allá de lo coyuntural, el PC jamás perdía la ocasión de señalar cuáles eran los caminos estratégicos que proponía para sacar a la Argentina de su condición atrasada y dependiente. Se trataba de una concepción "etapista", en la que se eslabonaban dos grandes momentos en el camino a transitar: si el objetivo final era el socialismo, antes sobrevendria la fase democrática. En efecto, el PC declaraba que "en la etapa actual de desarrollo de la vida económica y política de nuestro país es su propósito luchar en común con todas las fuerzas nacionales interesadas en dar una solución a los problemas de la revolución democrático-burguesa, agraria y antiimperialista". ${ }^{7}$ Una declaración similar se presentaba como primer item de los Estatutos partidarios, cuyo proyecto también fue girado a la base militante hacia la misma época, consagrando la estrategia frentepopulista de la revolución agraria y antiimperialista como parte inmanente de la identidad y la pertenencia comunista. ${ }^{8}$ El carácter no permanentista de la revolución por parte de

5. CC del PC, El camino argentino para asegurar el triunfo del pueblo en su lucha por la paz, el pan, la tierra, el bienestar social, la cultura, la democracia, la independencia nacional y el socialismo, Buenos Aires, Anteo, octubre 1956, p. 8 (ambas citas).

6. V. Codovilla, La nueva relación de fuerzas en lo internacional y nacional y el camino argentino hacia la democracia, la independencia nacional y el socialismo, Buenos Aires, Anteo, 1956, p. 39.

7. CC del PC, El camino..., p. 8.

8. Proyecto de Estatutos del Partido Comunista de la Argentina, Buenos Aires, Anteo, 1956, p. 3. 
los comunistas se complementaba con la obtención de la democracia como objetivo previo. Codovilla lo argumentaba con claridad en ese tiempo, cuando, para fundamentar cuál debía ser "el objetivo inmediato de nuestra lucha politica en la Argentina", sostenía: "Primero, conquistar el régimen democrático, y luego desarrollar la democracia 'hasta el fin'...". 9

Precisamente, según el proyecto de programa del PC, entre los objetivos fundamentales de la revolución estaba "la formación de un Gobierno de amplia coalición democrática que asegure al país un curso democrático y progresista de bienestar social, de cultura, de paz y de independencia nacional". Y era el Frente Democrático Nacional el encargado de luchar "por la realización de este programa y para conquistar el poder sin violencia, por la vía pacífica, parlamentaria, a no ser que se le cierre el camino democrático". ${ }^{10} \mathrm{El}$ nuevo énfasis que adquiría en el PC la cuestión de la vía no violenta del acceso al poder (al cual el partido renunciaba a encarar por fuera de dicho Frente) en parte se explica por la recepción de las nuevas concepciones "heterodoxas" que Jrushchov venía impulsando desde 1956. Codovilla las hacía suyas y las extendia al caso argentino: "El XX Congreso [del PCUS] al analizar la nueva correlación de fuerzas existente en el campo internacional [...] ha llegado también a la conclusión de que, en condiciones determinadas, es posible realizar la revolución socialista sin insurrección armada y desarrollarlas por la vía pacífica, utilizando para ese fin el parlamento [...] En lo que respecta a nuestro país, por ejemplo, es comprensible para cada uno que lo primero, lo inmediato, es la lucha para terminar con los gobiernos dictatoriales militares o civiles, para terminar con los golpes y contragolpes de Estado y conquistar un verdadero régimen democrático...". ${ }^{11}$

En todo caso, el Frente Democrático Nacional fue el deus ex machina de la estrategia comunista. En verdad, dicho organismo (también nominado a veces como "Patriótico de liberación nacional y social") nunca dejó de ser una entelequia en éste y en los períodos siguientes. No existieron siquiera los rudimentos de un intento serio de concreción de semejante experimento político. Además, el PC lo entendía a partir de límites enormes, reclamando que “...participen en él los obreros, los campesinos, los artesanos, los profesionales, los intelectuales, la pequeña y mediana burguesía y la burguesía nacional y sus partidos políticos y organizaciones sociales", advirtiendo que "mientras no exista un tal Frente, las fuerzas reaccionarias y proimperialistas -ora a través de maniobras politicas y aparentes concesiones, ora a través de la violencia-tendrán siempre la

9. V. Codovilla, La nueva..., p. 30.

10. Ambas citas de este párrafo en: $\mathrm{CC}$ del PC, El camino..., p. 8.

11. V. Codovilla, La nueva..., p. 19. 
posibilidad de imponerse a las fuerzas democráticas y antiimperialistas, a pesar de ser éstas la inmensa mayoria". ${ }^{12}$ Era clara su condición policlasista, lo que colocaba a los trabajadores en una situación de alianza estructural con otras fracciones sociales, pequeño burguesas y burguesas. La convocatoria a la organización de esa entidad ponía en cuestión los principios de la independencia de clase de los obreros, preceptos por los cuales supuestamente luchaba el PC. Pero la mayoría de los trabajadores venían de más de una década de formar parte del movimiento peronista, el cual los incorporaba masivamente entre sus filas, para subordinarlos políticamente a los intereses de la burguesía nacional. Sin aclarar cómo iba a recuperarse esa independencia perdida, apostando otra vez a una alianza con la burguesía nacional, el PC sólo podía aludir a una referencia general sobre la conducción de la clase obrera en el Frente: "le corresponde jugar el papel de unificadora, orientadora y dirigente de todas las fuerzas interesadas en una salida democrática y progresista de la situación actual, realizar la revolución agraria y antiimperialista y marchar hacia la sociedad socialista". ${ }^{13}$ En esta visión, la garantía de que todo ello ocurriese era la existencia de un poderoso partido comunista.

Las expectativas de que se verificara un proceso de fortalecimiento del PC parecían cobrar algún asidero a partir de 1957. Los comunistas completaron su reubicación en el movimiento obrero en una posición que procuraba sintonizar con las tendencias de lucha y reorganización características de la "resistencia peronista". Sin quedar muy asociados a la intervención militar que cayó sobre la CGT, el PC logró recuperar el control de varios gremios y pudo montar estructuras pequeñas pero sólidas en ese sector, al principio, en alianza con los peronistas: entre 1957-1958, la Comisión Intersindical y las primeras 62 Organizaciones. Posteriormente, con sus propias fuerzas y sectores independientes que le respondian, constituyó el grupo de "los 19". Finalmente, desde comienzos de los años 60, pudo poner en pie el Movimiento de Unidad y Coordinación Sindical (MUCS), desde el que impugnó el desarrollo de la nueva burocracia vandorista y sus políticas integracionistas (ver James, 1990; Schneider, 2006).

Por otra parte, el PC pudo participar en la elección de julio de 1957 para elegir los representantes de la Convención Constituyente, que eran los primeros comicios tras la caída del peronismo. Fue la instancia en que todos los partidos salieron a medir su grado de influencia, una suerte de "recuento globular", como sostuviera el dirigente socialista Américo Ghioldi. El justicialismo, proscripto, se encolumnó en el voto en

12. CC del PC, El camino..., p. 14.

13. CC del PC, El camino..., p. 12. 
blanco, logrando un 24,31 de los sufragios; las dos listas del radicalismo recién fracturado (UCRP y UCRI), alcanzaron el 45\% de los sufragios; a continuación, el PS, unido por última vez antes de la división de 1958, con 525.000 votos $(6,04 \%)$; más abajo, estuvo el PC, con 228.000 votos $(2,63 \%)$ (Cantón, 1973). Fueron electos tres comunistas en dicho cónclave, reunido en Santa Fe: Rodolfo Ghioldi, Pedro Tadioli e Irma Othar. El partido optó por participar de la elección y la asamblea, argumentando que con ello contribuirian a intentar impedir que el gran capital y la oligarquía suprimieran los principios democráticos de la Constitución Nacional o vetaran la aprobación de artículos favorables a los derechos obreros y populares como el 14 bis (que contó con el voto positivo de los comunistas).

\section{La denuncia de la "traición Frondizi" y la confianza en la burguesia nacional}

En las elecciones de febrero 1958, el PC decidió apoyar la fórmula presidencial finalmente triunfante de Frondizi-Gómez, de la UCR Intransigente, entendiendo que si bien ese partido no se habia pronunciado respecto a la necesidad o pertinencia de una coalición democrática para unir al pueblo argentino en torno a las grandes demandas nacionales, al menos había manifestado su acuerdo con una buena parte de los puntos programáticos de los comunistas. Estos sostenían que esa candidatura se había presentado bajo una campaña electoral centrada en el viejo "Programa de Avellaneda" del radicalismo, con reivindicaciones de lucha contra la oligarquía y el imperialismo y por transformaciones de fondo en la vida del país: reforma agraria, defensa de las riquezas nacionales como el petróleo y la energía eléctrica, mejoras en las condiciones de vida del pueblo, régimen democrático completo, plena libertad de acción para el movimiento obrero y popular, entre otras. ${ }^{14}$ Las expectativas del PC en el gobierno de Frondizi, asumido en mayo, fueron efimeras. Rescataron algunos de sus primeros discursos como presidente y ciertas medidas legislativas iniciales, a pesar de identificar ya crecientes vacilaciones en la aplicación del programa. Aún lo consideraban un momento progresivo en el proceso de conformación de una gran coalición para impulsar las tareas nacionales y democráticas. Así lo mantuvieron en sus materiales de carácter público: "Ahora el Partido Comunista pone todas sus fuerzas en tensión para llevar a la realidad

14. V. Codovilla, Las perspectivas de desarrollo de la situación nacional después de las elecciones del 23 de febrero, Buenos Aires, Anteo, 1958. 
el gran frente de la Democracia Argentina, que consolide y profundice la victoria del 23 de febrero...". ${ }^{15}$

Bastó el transcurrir de otros pocos meses de gobierno de Frondizi para que el PC reviera la caracterización del mismo y se colocara en la oposición, como puede advertirse en el informe de Codovilla a la reunión del CC ampliado de enero de 1959, luego editado bajo el título El plan Frondizi analizado a la luz de la situación internacional y nacional. A los grandes adelantos que estarian produciéndose en la URSS y el campo socialista (bajo el impulso de la reforma jrushchoviana y las crecientes conquistas de la República Popular China conducida por Mao Tse-Tung), junto al repliegue del poder y la influencia norteamericana, se añadian alli "los éxitos de los pueblos de América Latina en la lucha por su libertad e independencia", refiriéndose a la extraordinaria y reciente victoria de la revolución cubana dirigida por Fidel Castro, las caídas de las "dictaduras proyanquis" en Venezuela y Colombia, y los progresos politicos y electorales de fuerzas obreras, antiimperialistas y/o democráticas en Chile, Brasil y Uruguay. Incluso, aún colocaba en esta última perspectiva positiva "el triunfo electoral de las fuerzas obreras y democráticas de la Argentina, lo que, pese a las contradicciones en que se debate la política del país, permite mantener abierta la perspectiva de consolidación y desarrollo del régimen democrático" ${ }^{16}$

Pero en la visión de los comunistas, Frondizi acabaría abandonado el programa con el que habia triunfado en 1958, traicionando las aspiraciones democráticas y nacionales que el pueblo argentino había depositado en él. Los comunistas, una vez más, aparecían sorprendidos por los acontecimientos: aludian a una inesperada derechización del frondicismo. Lo acusaban de desprenderse de toda su inicial "base popular y progresista" y de autonomizarse del Parlamento y de los propios legisladores y colaboradores de la tradición partidaria, para entregarse a un equipo de técnicos antinacionales, "agentes de imperialismo yanqui", como Álvaro Alsogaray, y anteriores personeros liberales de la Revolución Libertadora. Lo impugnaban por adoptar un sistema presidencialista de corte personalista, que negaba la "esencia del régimen democrático" y que apelaba cada vez más a normas represivas para aplastar la oposición popular. Denunciaban su "plan de estabilización económica", trazado por el Fondo Monetario Internacional, que, a través de mecanismos de austeridad y sacrificios para las masas laboriosas, sólo resguardaban los beneficios de la gran patronal. Siguiendo este mismo análisis, la

15. Comisión Nacional de Propaganda del PC, Soluciones inmediatas para un gran plan, Buenos Aires, 1958, p. 15.

16. V. Codovilla, El plan Frondizi analizado a la luz de la situación internacional y nacional, Buenos Aires, Anteo, 1959. Las citas de este párrafo pertenecen a pp. 7-17. 
capitulación del gobierno de la UCRI ("gente de la pequeña burguesía y de la burguesia") ante la oligarquía terrateniente, el gran capital y los monopolios imperialistas no traería la estabilidad y mantendría la situación social y política en Argentina en estado de aguda conflictividad. Para el líder del PC: "El abandono del programa progresista de la UCRI y la defensa de los intereses tradicionales de la oligarquía agropecuaria, del gran capital y de los monopolios imperialistas que sigue el gobierno actual choca con la creciente resistencia de la clase obrera y del pueblo [...] luchas que el gobierno se propone yugular a través de las movilizaciones militares y del establecimiento del estado de sitio por tiempo indeterminado". ${ }^{17}$

Sin embargo, a pesar de la enorme decepción que implicaba haber depositado expectativas en Frondizi, la respuesta que encontraban Codovilla y el PC era la misma de antes, es decir, la de postular "la necesidad de crear un Frente Democrático Nacional y de formar un gobierno de amplia coalición democrática...", y luego precisaba "sólo con un tal frente amplio y con un gobierno que se apoye en él, y en el que estén representados la clase obrera y su partido, el Partido Comunista, es posible conseguir que los elementos pequeñoburgueses y burgueses dejen de lado sus vacilaciones y que junto con todo el pueblo enfrenten con éxito a las fuerzas de la reacción". ${ }^{18}$ Es decir, el papel que los comunistas se asignaban era, en definitiva, el de garantizar la consecución y coherencia del frente democrático, ubicando al partido y la clase obrera, en el papel de escolta atento y crítico de las fuerzas "pequeño burguesas y burguesas". Al mismo tiempo, propugnaba un amplio acuerdo de carácter obrero y popular para hacer frente a la ofensiva patronal-estatal, en un llamado que iba principalmente dirigido a las organizaciones sindicales peronistas y a los sectores progresistas del socialismo, el radicalismo del pueblo y la democracia cristiana.

Hacia febrero de 1959 el otro encumbrado dirigente del PC, Rodolfo Ghioldi, concluía su libro Acerca de la entrega. En el texto se denunciaba la rendición del gobierno al imperialismo norteamericano en todas las áreas (especialmente, la petrolera y la financiera), intentando demostrar las flagrantes contradicciones en que éste incurria ahora con sus retóricas a favor de la "libre empresa" y la "iniciativa privada" en relación al tradicional Programa de Avellaneda del radicalismo. Ghioldi concluía acerca de los límites de clase del frondicismo: "El hecho de la apostasía del señor Frondizi no es específicamente argentino, sino propio de la decadencia y decrepitud de ciertos sectores de una clase que, en defecto de un proletariado unido y capaz de cumplir su papel histórico,

17. V. Codovilla, El plan Frondizi..., p. 20.

18. V. Codovilla, El plan Frondizi..., pp. 24 y 57. 
capitula en tiempo más o menos breve ante el imperialismo y los grupos oligárquicos indígenas. Revela, además, la desnudez, desamparo y fragilidad de la ideología pequeño-burguesa". ${ }^{19} \mathrm{El}$ interrogante a plantear es por qué el PC, siendo consciente de estos rasgos de todo movimiento político de este tipo, no había alertado sobre esta inevitable evolución del frondicismo antes y durante la campaña electoral, o al comienzo de su gobierno. Asimismo, el corolario no prometía enseñanzas originales, pues el PC seguía insistiendo en la necesidad de conformar movimientos en donde los trabajadores fueran en unidad con esos sectores politicos burgueses y pequeñoburgueses, los mismos que habian dado vida al fenómeno de la UCRI.

A mediados de ese mismo año, en un volumen que compilaba entrevistas a los dirigentes de la izquierda, Ghioldi hacia nuevas y sugerentes precisiones teóricas: "El gobierno de Frondizi es lo opuesto del proceso democrático-burgués"; y más aún: "Los intereses de la burguesía nacional están en oposición al plan frondicista. En cambio lo aprueban no sólo los terratenientes y grupos oligárquicos, sino también la burguesía burocrática que crece parasitariamente al amparo de la maquinaria del Estado, y la parte de la burguesía que tiene atada su suerte a los monopolios extranjeros, y de los cuales es agente interior mediante migajas". ${ }^{20} \mathrm{El} \mathrm{PC}$ se preparaba para seguir convocando a una suerte de "auténtica burguesía nacional" a una alianza con la clase obrera. Y ella debía adoptar la forma de "frente popular", en el cual el partido reclamaba su lugar, tal como sostenía Ghioldi: otra vez, como respuesta al fracaso de un esbozo de Frente Democrático (el fallidamente encarnado por Frondizi) el PC proponía la constitución de otro de igual signo, con la misma composición social, aunque esperando un resultado diferente. La clase obrera debía seguir esperando que la burguesía nacional asistiera a la cita: "la experiencia muestra que sin la hegemonía de la clase obrera en la revolución democrático-burguesa, ésta queda a mitad de camino y se frustra, justamente porque la dirección burguesa implica, por razones de clase, la vacilación ante el imperialismo y la oposición al desarrollo político del proletariado. No cabe duda que la entrega del Gobierno al imperialismo hará que nuevos sectores de la burguesía nacional emprendan el camino de la lucha antiimperialista". ${ }^{21}$ La confianza se depositaba, nuevamente, en que la burguesía nacional, la mayor parte de la cual estaba sosteniendo al frondicismo, acudiese a la convocatoria del PC y aceptara una presencia directriz de los tra-

19. R. Ghioldi, Acerca de la entrega, Buenos Aires, Anteo, 1959, p. 59.

20. R. Ghioldi, "Reportaje”, en C. Strasser (ed.), Las izquierdas en el proceso politico argentino, Buenos Aires, Palestra, 1959, pp. 62-63.

21. R. Ghioldi, "Reportaje", p. 63. 
bajadores... El concepto estratégico quedaba en pie. Como apuntaba el por ese entonces joven intelectual partidario Juan Carlos Portantiero: "El fracaso del frondizismo no significa la caducidad de las ideas de la revolución democrático burguesa, sino la imposibilidad pequeño burguesa de conducirla". ${ }^{22}$

En la visión de los comunistas, el giro de la administración Frondizi a posiciones cada vez más reaccionarias no hizo sino profundizarse en 1959 y 1960. Además del estado de sitio y las diversas formas de represión al movimiento social, eso incluyó la proscripción políticoelectoral ya no sólo del peronismo, la cual venía existiendo desde hacía un lustro, sino también del propio PC. Frente a ello, los comunistas convocaron al voto en blanco en los comicios legislativos de marzo de aquel último año, en defensa de elecciones democráticas y en conjunto con los peronistas. Lo hicieron en repudio a un fraude que encontraban originado en el sometimiento gubernamental a los dictados del FMI y a los sectores oscurantistas del alto clero y de las fuerzas armadas, y que entendian como paso previo a una "dictadura abierta" (con o sin Frondizi). Obsérvese que el llamamiento del CC partidario a dicha acción concluía con las invariables exclamaciones a favor de recrear los mismos componentes sociales y programáticos que habian conducido a Frondizi al gobierno: "iQue se unan en la acción todas las fuerzas interesadas en una solución democrática y progresista, popular y nacional, y el plan colonizador del Fondo Monetario Internacional será derrotado en las elecciones del 27 de marzo y pronto llegará el momento en que el programa por el cual votó el pueblo el 23 de febrero será aplicado por un gobierno de amplia coalición democrática!". ${ }^{23}$

\section{Revolución Cubana y "giro a la izquierda" del peronismo}

Desde comienzos de 1961, las convocatorias del PC a formar amplias alianzas democráticas y progresistas adquirieron formas y destinatarios más concretos. Una vez más, fue Codovilla, en un informe a una reunión plenaria del CC partidario, el que intentó contextualizar esta política. ${ }^{24}$ En su óptica, los avances del campo del socialismo, la democracia y la

22. J. C. Portantiero, "Algunas variantes de la neoizquierda argentina”, en Cuadernos de Cultura, año XI, n 50, Buenos Aires, noviembre-diciembre de 1960, p. 61.

23. "Llamamiento del Comité Central del Partido Comunista a la clase obrera y al pueblo argentino para que voten en blanco el 27 de marzo y luchen por la anulación de las elecciones fraudulentas y por la realización de elecciones verdaderamente democráticas", Buenos Aires, Suplemento de Nueva Era, n 1, febrero de 1960.

24. V. Codovilla, Lo nuevo en la situación internacional y nacional. Informe rendido ante la reunión plenaria del Comité Central del Partido Comunista, realizada durante los dias 19 y 20 de mayo de 1961, Buenos Aires, Anteo, 1961. 
paz por sobre el del imperialismo, la reacción y la guerra continuaban su curso. Las evidencias de ello serian la anunciada entrevista que el presidente norteamericano Kennedy había tenido que aceptar con Jrushchov, los adelantos científico-técnicos de la URSS, las victorias anticolonialistas en Laos y Argelia, la derrota de la agresión yanqui contra Cuba y los progresos de la revolución en este último país (con la ayuda soviética). Apenas comenzaba a esbozarse el conflicto chinosoviético, que confirmaría el alineamiento del PC argentino con Moscú. La Alianza para el Progreso era definida como un intento imperialista de recuperar la iniciativa en el continente, sobre todo frente a la gesta caribeña dirigida por Fidel Castro, la cual Codovilla reconocía, sin mucha profundización, que de revolución democrática, agraria y antiimperialista se estaba transformando en socialista. Y en este marco, el viraje del gobierno frondicista a políticas entreguistas y patronales era completo, certificado con los cambios de gabinete y el nuevo plan económico, que se sumaba a su creciente anticomunismo. Frente a ello, se llamaba a la acción unitaria y combativa a la CGT y al conjunto de las organizaciones obreras, para enfrentar la ofensiva empresarial-estatal y las politicas reaccionarias del gobierno, tal como lo reclamaba el MUCS.

Como para tantos otros, también para el PC La Habana partía aguas: debía alzarse un extenso "frente democrático antiimperialista, de liberación nacional y social, que tiene como ejemplo a la Revolución cubana". Allí, junto a los comunistas, tendrian que agruparse los "peronistas no integracionistas", los "socialistas fieles al marxismo" (refiriéndose a quienes estaban en proceso de conformar el Partido Socialista Argentino de Vanguardia, PSAV), los "nuevos partidos antioligárquicos y antiimperialistas" y "las izquierdas existentes en los diversos partidos pequeño-burgueses y burgueses -que no renuncian a la lucha por incorporar a sus partidos a este frente- defensores de la Revolución cubana $\mathrm{y}$, por consiguiente, dispuestas a luchar en un frente común por la Revolución democrática, agraria y antiimperialista en nuestro país, así como aquellos sectores de las fuerzas armadas dispuestos a defender la libertad y la independencia nacional" ${ }^{25}$ Es decir, el PC ratificaba la necesidad de la misma estrategia democrático-burguesa y la análoga alianza policlasista y políticamente plural de siempre, pero en apoyo al proceso cubano. Pero ocurría que el castrismo en esos momentos estaba poniendo en cuestión dichas estrategia y alianzas, pues venía ensayando un camino de expropiación tanto al capital extranjero como a la "burguesía nacional" local. Estas contradicciones en las propias apuestas estratégicas y discursivas del partido de Codovilla y Ghioldi no podrian pasar desapercibidas mucho tiempo más para ciertos sectores internos.

25. V. Codovilla, Lo nuevo en la situación..., p. 43. 
El derrocamiento de Frondizi, el 29 de marzo de 1962, impuso ciertas readecuaciones a los postulados estratégicos del PC. Otra vez, Codovilla quedó encargado de fijar los criterios generales en un informe rendido en una reunión del CC ampliado realizado tres meses después de aquel hecho: se trató de El significado del "giro a la izquierda" del peronismo. ${ }^{26}$ En esta interpretación, el golpe militar "de tipo fascista" no habría sido tanto contra el gobierno de Frondizi (en tanto las politicas económica, social y exterior de éste era con escasas variantes la seguida luego por los golpistas), sino debido a la extrema debilidad de la administración de la UCRI; ella lo incapacitaba para mantener el orden público y reprimir las luchas en ascenso, cuya expresión más evidente era el "triunfo obrero y popular" en las fallidas elecciones para gobernador del 18 de marzo. Se habría tratado de una caída "sin pena ni gloria", de alguien que traicionó el mandato popular y el programa originariamente progresista con el que había accedido al poder. Según esta visión, tres camarillas militares y civiles aparecían constituidas: el "grupo ultragorila", rabiosamente antiperonista y anticomunista, que se proponía dejar de lado la fachada legal del endeble e inestable gobierno de José María Guido e implantar una "dictadura fascista abierta"; el "grupo aramburista", que proponía una "vía democrática controlada", con la proscripción de peronistas y comunistas; y un "grupo nasserista", dispuesto a instaurar una dictadura en base a confusos y demagógicos planteos nacionalistas y populistas. La línea partidaria debía ser la convocatoria a una gran alianza democrática, popular y progresista. ¿Con quién? Cada vez más, con los peronistas.

En efecto, la obsesión comunista por esos días era auscultar en las contradicciones internas de ese movimiento, para rechazar y aislar a sus sectores derechistas con el objetivo de potenciar y establecer acuerdos con los sectores de izquierda y obreros del mismo. Codovilla percibia que se estaba manifestando un nuevo "desarrollo de la conciencia política y de clase de las masas peronistas y de la mayoría de sus dirigentes", incluidas las estructuras sindicales como las 62 Organizaciones y la CGT, lo cual hacía más permeable la convocatoria unitaria de los comunistas y de su brazo sindical (el MUCS). Se lanzaban hipótesis osadas, ninguna de ellas finalmente corroboradas: "llegará el momento en que el 'giro a la izquierda' del peronismo lo llevará a fundirse, en igualdad de condiciones, con nuestro partido y otras fuerzas de izquierda, tales como los socialistas de vanguardia. Es así como se llegará a la formación del gran partido unificado de la clase obrera y el pueblo, basado en los principios del marxismo-leninismo, que [...] resolverá los problemas de

26. V. Codovilla, "El significado del 'giro a la izquierda' del peronismo" (julio 1962), en Trabajos escogidos, tomo I, Buenos Aires, Anteo, 1972. 
la revolución agraria y antiimperialista y pondrá proa firme hacia el socialismo". Con el PSAV, las expectativas eran todavía mayores: "Es de saludar [...] la actitud del Partido Socialista Argentino de Vanguardia que, después de haber eliminado de su seno a trotskistas y aventureros políticos, ha adoptado posiciones marxistas-leninistas que en su desarrollo ulterior lo llevarán a la formación de un partido único con el Partido Comunista". ${ }^{27}$ Claro que las apuestas a formar algún día un gran partido único de la izquierda con peronistas y socialistas, no modificaban los objetivos permanentes del PC, cuyas perspectivas siempre eran anunciadas como inminentes: "Están madurando las condiciones para la formación del gran Frente Democrático antioligárquico, antiimperialista y pro paz". Los invitados a dicha coalición no se alteraban: "Se incorporarán a esta lucha sectores de la burguesía nacional y de la pequeña burguesía que en este momento están profundamente afectados por la política económica del gobierno". ${ }^{28}$

Dos meses después, en septiembre de 1962, Codovilla ratificaba que, a no ser que los caminos para la conquista pacífica del gobierno fuesen clausurados por los círculos dirigentes, el PC apostaba a una toma del poder no violenta, sin excluir la acción electoral, con la participación de las amplias masas y en alianza con sectores de la burguesía nacional. Pero esta aclaración ahora se hacía, sintomáticamente, frente a una hipotética discusión con planteos de lucha armada, que comenzaban a despuntar en la Argentina y que se multiplicarán con el paso de los años, fuera, cerca y dentro del propio PC: "Hay algunos camaradas que plantean la cuestión del modo siguiente: Estamos de acuerdo con que la lucha de masas lo decide todo, pero, ¡no se podria acelerar el proceso a través de las guerrillas? ¿No es este un camino más corto? Seria el más corto si fuera acompañado de la acción de masas y para que las masas marchen en esa dirección es preciso que se convenzan por su propia experiencia que este y no otro es el camino que deben seguir". ${ }^{29}$

Fue con estas herramientas teórico-políticas, articuladas en torno a los anhelos de la revolución agraria antiimperialista de curso seguramente pacífico y el Frente Democrático Nacional como su instrumento, ideas maceradas y reconfirmadas bajo diversas coyunturas y combinadas con múltiples tácticas, que el PC preparó y finalmente desarrolló su tan postergado XII Congreso Nacional. El cónclave se realizó entre fines de febrero y principios de marzo de 1963 en la ciudad de Mar del Plata, constituyendo una puesta a punto de los planteamientos programáticos

27. V. Codovilla, “El significado...”, pp. 243-244 y 247 (ambas citas).

28. V. Codovilla, "El significado...”, pp. 249 y 252.

29. V. Codovilla, "Se fortalece la unidad popular en la Argentina” (septiembre de 1962), en Trabajos escogidos, tomo I, Buenos Aires, Anteo, 1972, pp. 264-265. 
de la organización. ${ }^{30}$ En respuesta a ellos, con el paso del tiempo, se irá desplegando la impugnación de varios grupos y corrientes de izquierda dentro del partido, que pondrán fin a un ciclo de relativa homogeneidad interna (Aricó, 1988; Tortti, 1999; Prado Acosta, 2013). La crisis del PC, su "malestar", la discusión de su línea, serán temas recurrentes de la izquierda sesentista.

$$
* * *
$$

Para el PC argentino la estructura económico-social del país estaba sujeta a un tipo de capitalismo, dependiente y atrasado. Por el modo en que este planteo estaba argumentado, ya desde los 30, la paradoja resultaba obvia: el autodenominado "partido de la clase obrera" terminaba identificando como problema principal del país no al capitalismo, sino al insuficiente desarrollo del mismo. Según este análisis, la industria vernácula había quedado constreñida en límites estrechos y el sector rural estaba sometido a un régimen de explotación ineficiente y caduco, todo distorsionado por el peso asfixiante del capital monopolista extranjero y la oligarquía terrateniente. En esos marcos, la burguesía nacional aparecía imposibilitada, objetivamente, de asegurar un camino de "independencia y progreso", pero dado que presentaba contradicciones con el imperialismo, ocupaba un lugar clave en la interpelación comunista. Habia, pues, un enemigo central, que era el imperialismo, en alianza con el "gran capital intermediario" y a los "latifundistas de tipo feudal", con lo cual la contradicción entre la clase obrera y la burguesía nacional quedaba relegada a un segundo plano y subalternizada en la orientación del PC.

Se declamaba la necesidad de una "hegemonía obrera" en el Frente Democrático Nacional, pero para que la burguesía nacional llevase hasta el fin ciertos objetivos, cumpliendo así el papel histórico asignado. En verdad, a la clase obrera y "su partido" lo que se le adjudicaba era el papel de consejeros y aliados críticos. Ello se expresó en el modo como el PC realizó el balance del período justicialista, se ubicó en el ciclo de la Revolución Libertadora, depositó su confianza en el frondicismo hacia 1957-1958, procesó luego la "traición" y el "abandono del programa" por parte de ese gobierno y más tarde pautó los objetivos para los cuales se pensaba una fusión con las masas peronistas (en pleno "giro a la izquierda") y con los socialistas de izquierda en 1962. En todos los casos, la independencia de la clase obrera quedaba lesionada ante una convocatoria policlasista, en donde la presencia de los capitalistas

30. V. Codovilla, Por la acción de masas hacia la conquista del poder. Informe rendido al XII Congreso del Partido Comunista, Buenos Aires, Anteo, 1963. 
"nacionales" tornaba inevitablemente burguesa a dicha coalición. La autonomía de la clase obrera se negaba en el planteamiento comunista por una vía distinta a la del peronismo. El PC reconocía que este movimiento era "una forma de introducción de la ideología burguesa" entre los trabajadores. Pero si el peronismo significaba la subordinación ideológica y la disolución de la clase obrera en un movimiento nacionalista burgués, cabía preguntarse si el programa y la estrategia comunista no expresaban una renuncia o incapacidad de liberar a dicha clase de la hegemonía burguesa, al propiciar un tipo de revolución y un instrumento político permanente (el Frente Democrático Nacional) que estipulaba una alianza estructural de los trabajadores con los capitalistas nacionales. Ese será uno de los ángulos de crítica al PC que desplegarán la izquierda revolucionaria y la "nueva izquierda" sesentista. Asimismo, la renuncia a la disputa por el poder por parte de la clase obrera y de su partido era un presupuesto básico de la estrategia comunista de revolución democrático-burguesa, agraria y antiimperialista. Si el destino era el acceso a la conducción del Estado por el denominado Frente Democrático Nacional (en donde el PC intervendría), no hay sino referencias excesivamente ambiguas acerca del modo en que este hecho ocurriria, salvo las alusiones al uso de las vías pacíficas o parlamentarias, cuya clausura podria replantear dicha alternativa sin indicar cuales otras estarian enunciadas como repertorio posible.

La moderación política exhibida por el PC, en definitiva, era la de su programa y de todo su planteo estratégico. Esta era una certidumbre aún antes de que aparecieran las tendencias a la radicalización ideológica de los años 60, incentivadas en América Latina con especial vigor a partir del triunfo y expansión de la revolución cubana. Cuando ellas se propagaron, la capacidad del partido para resistirlas debió ponerse a prueba. El destino del PC a partir de 1963 fue el de un constante desafio de sectores internos que, en muchos casos de manera confusa (y con una mezcla contradictoria de gramscismo, castro-guevarismo y maoís$\mathrm{mo})$, levantaron un cuestionamiento a las concepciones, dogmáticas, etapistas y/o pacifistas de la revolución propias del partido, así como a su confianza permanente en la burguesía nacional. Se abrió entonces una era de rupturas y expulsiones en las filas comunistas, que produjo una retahíla de grupos: entre otros, el centrado en la revista Pasado y Presente (animado desde Córdoba por José Aricó y apoyado en Buenos Aires por Portantiero y su sigla Vanguardia Revolucionaria); el que impulsó la revista La Rosa Blindada; los que confluyeron luego en las FAL y las FAR. Una "nueva izquierda" despuntó en la escena encontrando en el PC un sinónimo de una vieja izquierda reformista, caduca y anquilosada. Muchos entendieron que el origen del problema estaba en el modo en que el partido de Ghioldi y Codovilla concebía su programa. 


\section{Bibliografia}

Altamirano, Carlos (2011), Peronismo y cultura de izquierda, Buenos Aires: Siglo XXI.

Amaral, Samuel (2008), La renuencia de las masas: el Partido Comunista ante el peronismo: 1945-1955, Buenos Aires: Universidad del CEMA.

Arévalo, Oscar (1983), El Partido Comunista, Buenos Aires: CEAL.

Aricó, José (1988), La cola del diablo. Itinerario de Gramsci en América Latina, Buenos Aires: Puntosur.

Camarero, Hernán (2012) "Ascenso y ocaso del Partido Comunista en el movimiento obrero argentino: crítica historiográfica y argumentaciones conceptuales", en Archivos de historia del movimiento obrero y la izquierda, año I, $\mathrm{n}^{\circ} 1$, septiembre, Buenos Aires, pp. 57-79.

- (2013) "Antiguas controversias, nuevos enfoques: clase obrera, sindicalismo y comunismo en la Argentina durante la primera mitad del siglo XX. Un estado de la cuestión", en PolHis (revista del Programa Buenos Aires de Historia Política), año VI, $\mathrm{n}^{\circ} 11$, primer semestre, Buenos Aires, pp. 129-146.

Campione, Daniel (2007), "El Partido Comunista de la Argentina. Apuntes sobre su trayectoria”, en E. Concheiro Bórquez, M. Modonesi y H. Crespo (cords.), El comunismo: otras miradas desde América Latina, México: UNAM, pp. 167-215.

Cantón, Darío (1973), Elecciones y partidos politicos en la Argentina. Historia, interpretación y balance: 1910-1966, Buenos Aires: Siglo XXI.

Cernadas, Jorge, Roberto Pittaluga y Horacio Tarcus (1998), "La historiografia sobre el Partido Comunista de la Argentina. Un estado de la cuestión", El Rodaballo, año IV, n 8, Buenos Aires, 1998, pp. 30-39.

Fava, Athos (1983), Qué es el Partido Comunista, Buenos Aires: Sudamericana.

Gilbert, Isidoro (1994), El oro de Moscú. La historia secreta de las relaciones argentino-soviéticas, Buenos Aires: Planeta.

- (2009), La Fede. Alistándose para la revolución. La Federación Juvenil Comunista, 1921-2005, Buenos Aires: Sudamericana.

Gurbanov, Andrés y Sebastián Rodríguez (2008), "La compleja relación entre el Partido Comunista argentino y el peronismo (1943-1955)", ponencia en Primer Congreso de Estudios sobre el Peronismo: la primera década, Mar del Plata.

Jáuregui, Aníbal (2012), "El peronismo en los debates del Partido Comunista Argentino: 1945-1953", en A Contracorriente. A Journal on Social History and Literature in Latin America, North Carolina State University, vol. IX, $\mathrm{n}^{\circ}$ 3, primavera, Raleigh, North Carolina, pp. 22-40, www.ncsu.edu/ project/acontracorriente.

James, Daniel (1990), Resistencia e integración. El peronismo y la clase trabajadora argentina, 1946-1976, Buenos Aires: Sudamericana. 
Prado Acosta, Laura (2013), “Sobre lo ‘viejo’ y lo ‘nuevo': el Partido Comunista argentino y su conflicto con la Nueva Izquierda en los años sesenta", en A Contracorriente. A Journal on Social History and Literature in Latin America, North Carolina State University, vol. XI, $n^{\circ} 1$, otoño, Raleigh, North Carolina, pp. 63-85, www.ncsu.edu/project/acontracorriente.

Penella, Claudio y Marcelo Fonticelli (2007), La prensa de izquierda y el peronismo (1943-1949). Socialistas y comunistas frente a Perón, La Plata: EDULP.

Schneider, Alejandro (2006), Los compañeros. Trabajadores, izquierda y peronismo (1955-1973), Buenos Aires: Imago Mundi.

Staltari, Silvana (2014), "Los falsos apóstoles contra la demagogia peroniana: el Partido Comunista frente a la politica social del peronismo", Investigaciones y Ensayos, n 60, Buenos Aires, pp. 459-490.

Tortti, María Cristina (1999), "Izquierda y 'nueva izquierda' en la Argentina. El caso del Partido Comunista”, en Sociohistórica. Cuadernos del CISH, $\mathrm{n}^{\circ}$ 6, Universidad Nacional de La Plata, segundo semestre, pp. 221-232.

Resumen: Este artículo examina las posiciones y la actuación del Partido Comunista en la Argentina en 1955-1963, periodo signado por la caída del peronismo, la Revolución Libertadora y el gobierno de Frondizi. En particular, se estudia el modo en que el PC caracterizó al capitalismo local como dependiente, atrasado y con rasgos semifeudales, constreñido por el peso de los monopolios extranjeros y la oligarquía terrateniente, y las razones por las cuales planteó la necesidad de una "revolución democrático-burguesa, agraria y antiimperialista", es decir, una revolución por etapas, que postergaba para un futuro lejano el horizonte socialista. Se analiza la permanente convocatoria del PC a la formación de un Frente Democrático Nacional y a acuerdos con sectores de la burguesía nacional.

Palabras clave: Partido Comunista de Argentina - Revolución democrática Frente Democrático - Burguesía Nacional

Abstract: This article examines the positions and actions of the Communist Party in Argentina in 1955-1963, a period marked by the fall of Peronism, the "Revolución Libertadora" and the government of Frondizi. It studies the way the PC characterized to the local capitalism with a dependent and semi-feudal traits, constrained by the weight of foreign monopolies and oligarchy. It explores how the $\mathrm{PC}$ raised the need for a "bourgeois-democratic, agrarian and anti-imperialist revolution", which deferred to the distant future the socialist horizon. The calling to the formation of a "National Democratic Front" and the agreements with sectors of the national bourgeoisie is analyzed.

Keywords: Communist Party of Argentina - Democratic Revolution - Democratic Front - National Bourgeoisie

Recepción: 7 de junio de 2014. Aprobación: 6 de agosto de 2014 . 